\title{
Images as proximity sensors: the incidence of conspecific foraging in Antarctic fur seals
}

\author{
Sascha K. Hooker ${ }^{1 *}$, Tatsiana Barychka ${ }^{2,3}$, Mark J. Jessopp ${ }^{4}$ and lain J. Staniland ${ }^{5}$
}

\begin{abstract}
Background: Although there have been recent advances in the development of animal-attached 'proximity' tags to remotely record the interactions of multiple individuals, the efficacy of these devices depends on the instrumentation of sufficient animals that subsequently have spatial interactions. Among densely colonial mammals such as fur seals, this remains logistically difficult, and interactions between animals during foraging have not previously been recorded.
\end{abstract}

Results: We collected data on conspecific interactions during diving at sea using still image and video cameras deployed on 23 Antarctic fur seals. Animals carried cameras for a total of 152 days, collecting a total of 38,098 images and 369 movies (total time $7.35 \mathrm{~h}$ ). Other fur seals were detected in $74 \%$ of deployments, with a maximum of five seals detected in a single image ( $n=122$ images, 28 videos). No predators other than conspecifics were detected. Detection was primarily limited by light conditions, since conspecifics were usually further from each other than the $1-\mathrm{m}$ range illuminated by camera flash under low light levels. Other seals were recorded at a range of depths (average $27 \pm 14.3 \mathrm{~m}$, max $66 \mathrm{~m}$ ). Linear mixed models suggested a relationship between conspecific observations per dive and the number of krill images recorded per dive. In terms of bouts of dives, other seals were recorded in five single dives (of 330) and 28 bouts of dives $<2$ min apart (of 187). Using light conditions as a proxy for detectability, other seals were more likely to be observed at the bottom of dives than during descent or ascent. Seals were also more likely to be closer to each other and oriented either perpendicular or opposing each other at the bottom of dives, and in the same or opposite direction to each other during ascent.

Conclusions: These results are contrary to animal-attached camera observations of penguin foraging, suggesting differing group-foraging tactics for these marine predators. Group foraging could have consequences for models linking predator behaviour to prey field densities since this relationship may be affected by the presence of multiple predators at the same patch.

Keywords: Pinniped, Animal-attached camera, Sociality, Foraging, Groups, Arctocephalus gazella

\section{Background}

Marine mammals spend the vast majority of their lives in relatively inaccessible environments in the open ocean and at depth. Animal-attached biotelemetry instrumentation has revolutionised the measurement of their behaviour in such environments [1] but generally such

\footnotetext{
*Correspondence: s.hooker@st-andrews.ac.uk

1 Sea Mammal Research Unit, Scottish Oceans Institute,

University of St Andrews, Fife KY16 8LB, UK

Full list of author information is available at the end of the article
}

tags sample only a focal individual. In rare cases when two tagged animals interact, synchrony of behaviour can be observed, but this very much depends on the fortuitous interaction of two instrumented animals [2].

For pinnipeds, there is a wide dichotomy in our understanding of sociality ashore versus at sea. Their social systems while ashore are well documented and there are even suggestions of long-term recognition among animals [3-6]. However, information on the social environment of animals at sea is scarce and yet this environment 
can be crucial to their foraging success [7]. Social facilitation of foraging has been observed among several species of cetacean [8-10] and so might be expected for many pinniped species, particularly those that forage on shoaling prey.

Antarctic fur seals (Arctocephalus gazella) feed primarily on Antarctic krill (Euphausia superba), a densely shoaling prey species [11]. During the breeding season lactating female Antarctic fur seals are central place foragers, foraging offshore for approx. 5-7 days and then returning to feed their pup [1]. During this time their capture and recapture for instrument deployment and recovery is straightforward. Almost all of our current knowledge of their at-sea behaviour is, therefore, gleaned from animal-attached tags. These have included satellite transmitters and time-depth recorders, which have shown the foraging movements of individual animals in great detail (e.g., [12-14]), but provide no information on the presence of other animals foraging alongside instrumented seals.

Among other marine mammal species, observation of animals at sea can provide information on grouping and sociality at sea. While some ship-board surveys have been conducted which have recorded Antarctic fur seals, these rarely document the sociality or group-sizes of seals at sea, presumably due not only to difficulty in definition of functional group size but also to issues with bias of sightings towards larger groups of animals. For example, surveys around the South Georgia area, one of the largest breeding sites for Antarctic fur seals in the southern ocean, have primarily described only the number of seals per unit of distance or time (e.g., 1.5-5.2 seals $/ \mathrm{km}$, [15]), although one survey noted that 1208 fur seals were observed in 361 records, i.e. an average group size of 3.3 animals/record [16].

Animal-attached proximity tags could provide a solution for the collection of data on social interactions remotely [17]. These tags can record approximate proximity (based on received signal strength indicator) between individuals. However, for best results they require comprehensive sampling of the local population. As population sizes increase, this approach becomes more difficult. The population size of Antarctic fur seals on Bird Island was estimated to number over 60,000 breeding females in 1990 [18]. Tagging 100 of these 60,000 animals ashore, and conservatively overestimating group sizes at sea at ten animals, we would need, on average, to sample movements of the focal animal interacting with 1000 groups to make only 20 detections of other tagged animals. Thus, using a proximity tag approach to record interacting fur seals at sea is not yet feasible.

An alternative approach to examine sociality of animals at sea is to use animal-attached cameras. Previously these have been used in conjunction with multiple time-depth recorder deployments to examine synchrony in diving behaviour $[19,20]$. Only one study of penguins has examined sociality during at-sea foraging using animalattached cameras on single focal animals [21].

Here we examine the use of animal-attached cameras to collect information on conspecific female Antarctic fur seals during diving behaviour. We examine: (1) when and how often other seals are seen, (2) the relationship between presence of other seals and parameters such as dive depth and whether dives are part of long or short bouts and (3) the orientation and distance of seals relative to each other.

\section{Methods}

A digital camera and time-depth recorder package $(10.5 \times 8.5 \times 5.5 \mathrm{~cm}, 700 \mathrm{~g}$, Wild Insight Ltd, UK) was deployed on 23 lactating female Antarctic fur seals during the months of December-February of austral summers 2000, 2001 and 2002 at Bird Island, South Georgia $\left(54^{\circ} \mathrm{S}, 38^{\circ} \mathrm{W}\right)$. Full details on the camera and attachment are provided in Hooker et al. [22]. In brief, we selected larger females with a healthy pup. Seals were captured and held using standard methods. Each seal was weighed ( $\pm 0.5 \mathrm{~kg}, 100-\mathrm{kg}$ Salter spring scale), measured for length and pectoral girth $( \pm 0.5 \mathrm{~cm})$, and a numbered white plastic cattle ear rototag (Jumbo Tags, Dalton, Henleyon-Thames, UK) was placed in the trailing edge of each foreflipper. The camera tag was attached using cable ties to nylon webbing which was glued (quick-setting epoxy) to the fur of the seal. A 40-g, $165 \mathrm{MHz}$ radio-transmitter (Sirtrack Ltd, Havelock North, New Zealand) was also fitted to the fur directly behind the camera to enable relocation when the animal returned to shore. Radio signals were monitored with an automated scanning receiver located less than $100 \mathrm{~m}$ from the point at which seals were captured. The animal was recaptured upon its return to the colony, at which time it was reweighed and the camera was recovered by cutting the cable ties, leaving the webbing attached to the animal's fur until it was moulted at the end of the summer season.

Each animal was instrumented for a single foraging trip (5-7 days, Table 1$)$. The instrument contained a digital camera interfaced with a time-depth-light recorder (Mk 7 or Mk 9 TDR, Wildlife Computers, USA) such that the camera was triggered at depths greater than $10 \mathrm{~m}$ (as described in Hooker et al. [22]). The camera collected still images at 3-s intervals in anterior orientation (17 deployments) or video at frame rates of approx. 5-10 frames per sec facing in anterior $(n=2$ seals $)$ or posterior $(n=4$ seals) orientations (Table 1$)$. The camera contained an LED flash, which allowed illumination to $1 \mathrm{~m}$ in dark conditions [22]. The flash illuminated in the 


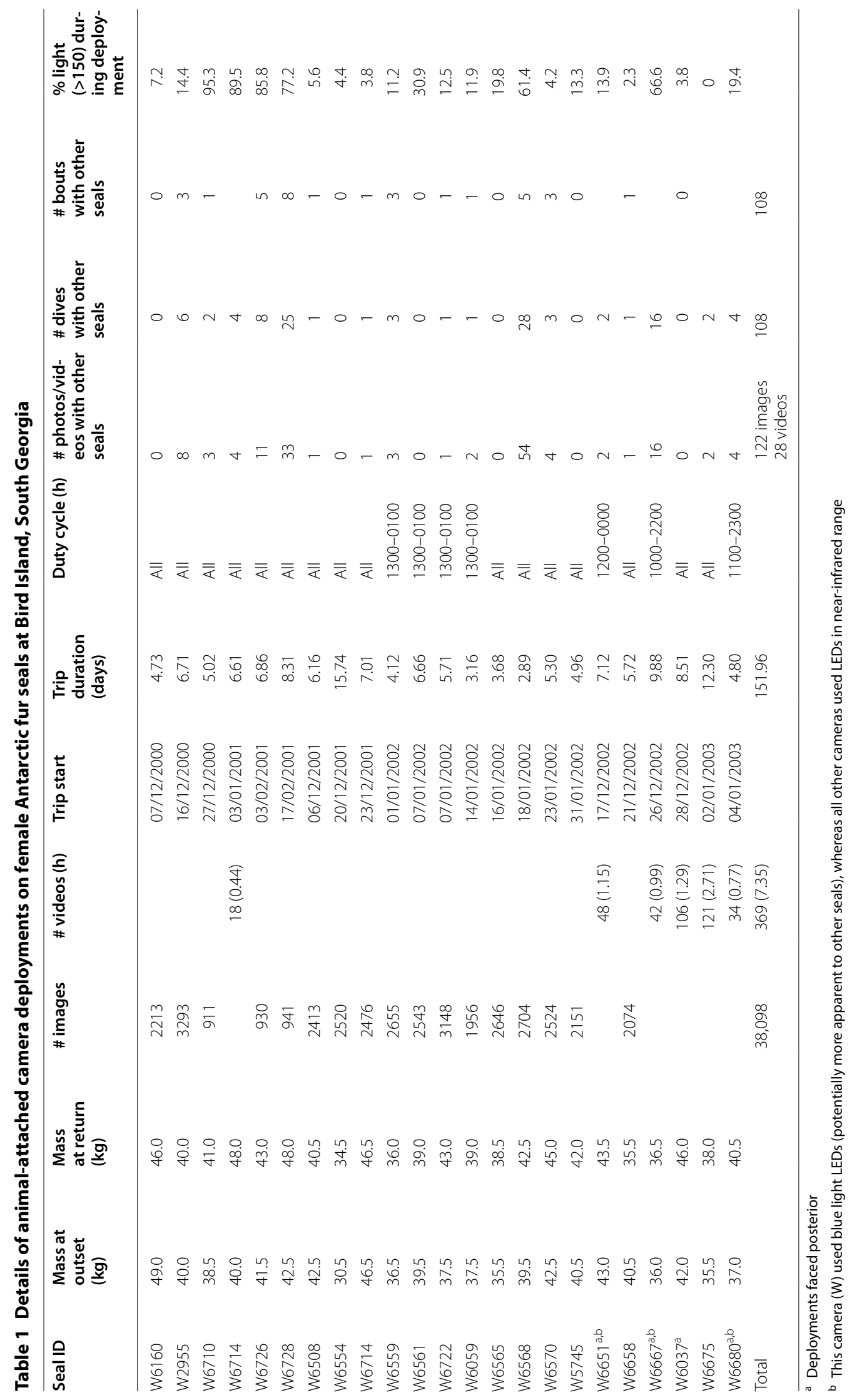


near-infrared region of the spectrum for all deployments except four which faced posteriorly and for which an alternative blue light LED was used to provide increased illumination (Table 1). For seven deployments the camera was duty cycled to provide data over a longer portion of the trip (Table 1).

The light sensor on the TDR sampled blue-light intensity in $\mathrm{W} / \mathrm{cm}^{2}$ converted to a log-scale spanning the range from dark (reading 25 at approximately $5 \times 10^{-12} \mathrm{~W} /$ $\mathrm{cm}^{2}$ ) to bright (reading 225 at $5 \times 10^{-2} \mathrm{~W} / \mathrm{cm}^{2}$ ). The images taken by camera also provide an indication of the camera's reaction to the surrounding light, since the camera shutter speed varied automatically (ranging from $1 / 4$ to $1 / 4000 \mathrm{~s}$ ) depending on the ambient light level, and the automatic gain control set the light level of the picture to maximise image contrast. The light intensity for each image was obtained by converting the colour (RGB) picture to greyscale (NTSC) and summing the greyscale luminance values across all pixels.

Krill were observed in many images. These were scored for certainty of identification $(1=$ unidentifiable biomass, $2=$ blurred/indistinct but eye stripes identify krill, $3=$ visible/distinct krill). Krill were scored by two observers and error-checked by a third to ensure consistency. Bouts were defined (based on preset camera operation) as separated by $2 \mathrm{~min}$ at $<10 \mathrm{~m}$ [22]. Dive characteristics such as depth and position of the animal within the dive (descending, at bottom $>75 \%$ max depth, ascending and at surface) were calculated using customwritten code in MATLAB. Encounter rate statistics were calculated for each dive for images containing other seals (seal encounter rate $=$ total other seals observed/ total number of images), and for images containing krill prey (krill encounter rate $=$ total krill biomass (approximate log scale) observed/total number of images). Mixed modelling was used to account for some of the variability attributed to differences between individual seals. A linear mixed model was used to explore the relationship between encounter rate of other seals and krill encounter rate of two different certainty scores (KER1, >1; and KER2, >2), maximum dive depth (Depth), dive time (Time), and austral year (Year). The intercept was permitted to vary randomly across seals. The model was of the following form:

$$
\begin{aligned}
y_{i j}= & \beta_{0}+a_{i}+\beta_{1} \operatorname{KER}_{i j}+\beta_{1} \mathrm{KER}_{i j} \\
& +\beta_{3} \operatorname{Depth}_{i j}+\beta_{4} \text { Time }_{i j}+\beta_{5} \text { Year }_{i j}+\varepsilon_{i j},
\end{aligned}
$$

where $y_{i j}$ was the encounter rate of other seals on the $j$ th dive from the $i$ th animal, $\beta_{0}$ was the overall intercept, $a_{i} \sim N\left(0, \sigma^{2}\right)$ was the random effect (the intercept) of the $i$ th animal; $\beta_{1}, \beta_{2}, \beta_{3}, \beta_{4}$ and $\beta_{5}$ were coefficients; and $\varepsilon_{i j}$ was the residual random error term. Analysis was performed using the lme package in R 3.0.1 ( $\mathrm{R}$ Core Team, 2013). We used Akaike Information Criterion (AIC) and model simplification (anova) for parameter selection. Model fit was assessed using standardised residuals and QQ-plots.

Images were examined in terms of orientations and distances of other seals from the focal animal. Orientation was scored in terms of whether the observed seal was moving in the same direction as the tagged animal, perpendicular to it, or swimming towards it. Distance between the two seals was estimated using knowledge of the camera field of view $\left(30^{\circ} \times 24^{\circ}\right)$, assuming a body length of $125 \mathrm{~cm}$, and examining the length of the seal on image (correcting for estimated angle from perpendicular). In this manner, another seal would fill the horizontal aspect of the image at $2.3 \mathrm{~m}$ away, and would fill a quarter of the image at $9.3 \mathrm{~m}$ away.

\section{Results and discussion}

The southern ocean ecosystem is relatively simple, with several predator species feeding on a single keystone prey species, the Antarctic krill [23, 24]. Despite the sympatry of many krill predators around South Georgia, and speculations about the presence of direct interspecies competition between these krill predators [25, 26], we have not observed images of any predators other than conspecifics foraging alongside instrumented seals.

The majority of deployments (17 of 23) contained images or footage showing other seals. In total, 122 images and 28 videos were recorded which showed the presence of other seals (Table 1; Figs. 1, 2). Of these images, the majority $(n=107)$ showed only one other seal, 12 showed two other seals, and 3 showed three other seals. Among the video records, almost all observations were of a single seal in an image frame, and we were unable to identify whether these were repeated observations of the same individual. However, one frame showed five other seals at the surface ahead of the ascending seal. It should be noted that the camera had only a $30^{\circ}$ by $24^{\circ}$ field of view. Thus it took only $1 / 180$ of the potential sphere of view surrounding the focal seal. This method was, therefore, highly unlikely to sample all of the seals within a group, but did provide an indication of other seal presence.

One concern using animal-attached instrumentation is the potential effect of the instrument on the behavior being recorded. In this case, the primary concerns were with the additional weight and drag of the camera and the effect of the LEDs. Comparison of behaviour with and without cameras showed that additional drag tended to affect dive duration and bottom time, but not trip duration [27]. The LEDs used in all 17 still-image deployments and 3 video deployments were in the near-infrared region of the spectrum, to 

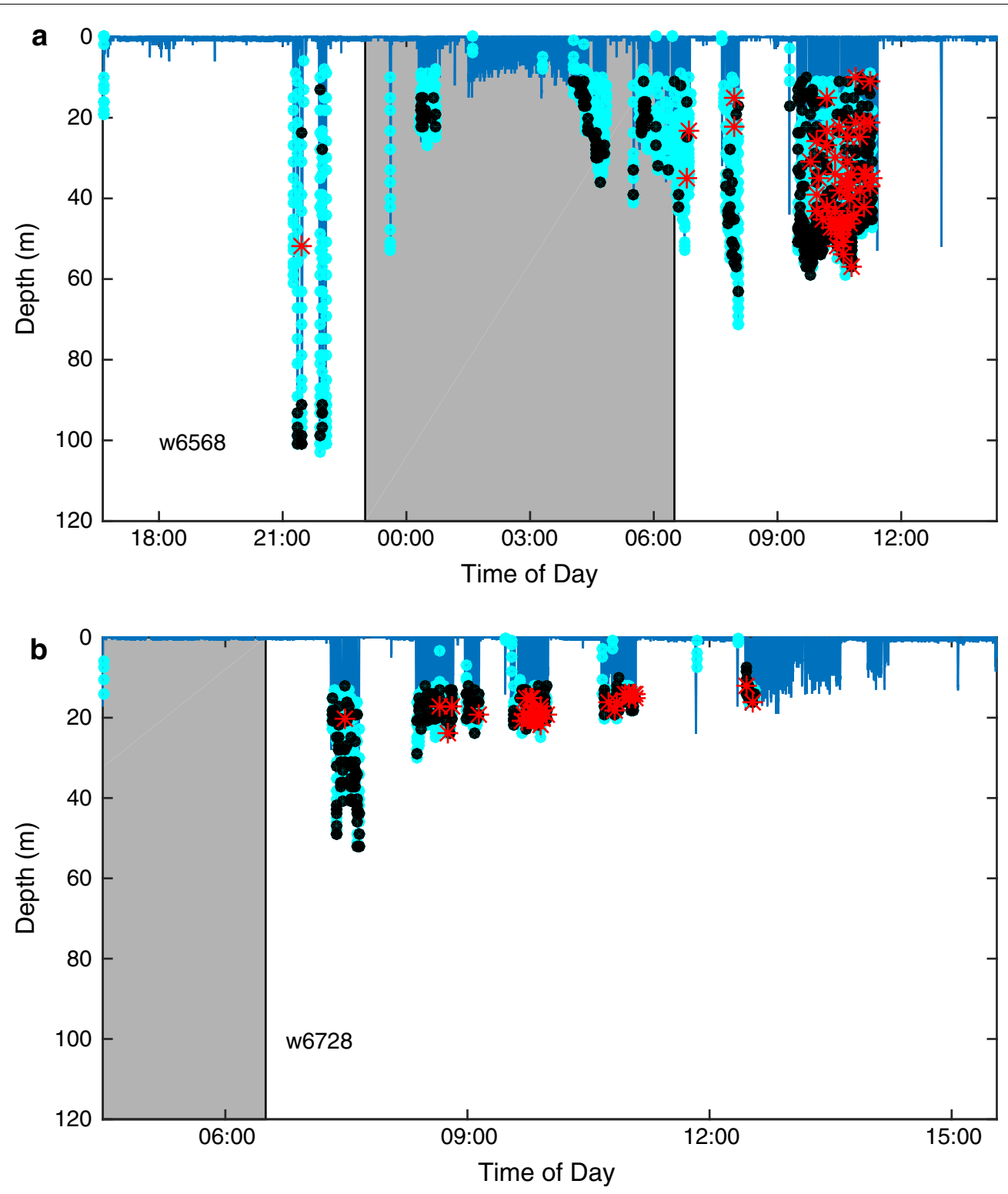

Fig. 1 Example dive profiles (depth vs. time) shown as blue line trace for seals $\mathbf{a}$ w6568 and $\mathbf{b}$ w6728. Cyan shows locations at which images were recorded, black shows presence of krill, red shows presence of other seals in the image. Grey hatching shows periods of darkness 11.30 p.m.6.30 a.m. GMT

minimize detection likelihood by fur seals and Antarctic krill. Heaslip and Hooker [27] also explored this issue in some detail, contrasting behaviour recorded with/without active flash, and found no major differences caused by flash presence. However, three of the video deployments used a camera with blue-light LEDs to maximize illumination (Table 1). These were more likely to be detected by other seals and so could have triggered some inquisitiveness from any nearby conspecifics (increasing likelihood of their detection). We limited further exploration of the data to the still images to minimize confounding variables.
The majority of images containing other seals were recorded in conditions with downwelling light (i.e. not during dark conditions illuminated only by camera flash, Fig. 3). The detection of other seals was correlated with good light conditions, defined as the proportion of images with corresponding TDR light sensor readings $>150$, i.e. equivalent to surface at dusk; Pearson correlation 0.51 (Table 1; Fig. 1). This was to be expected, since initial camera tests showed that the flash could illuminate reflective objects (such as krill eyes) at only 1-2 m distance ([22]). The matt body of another fur seal would, 


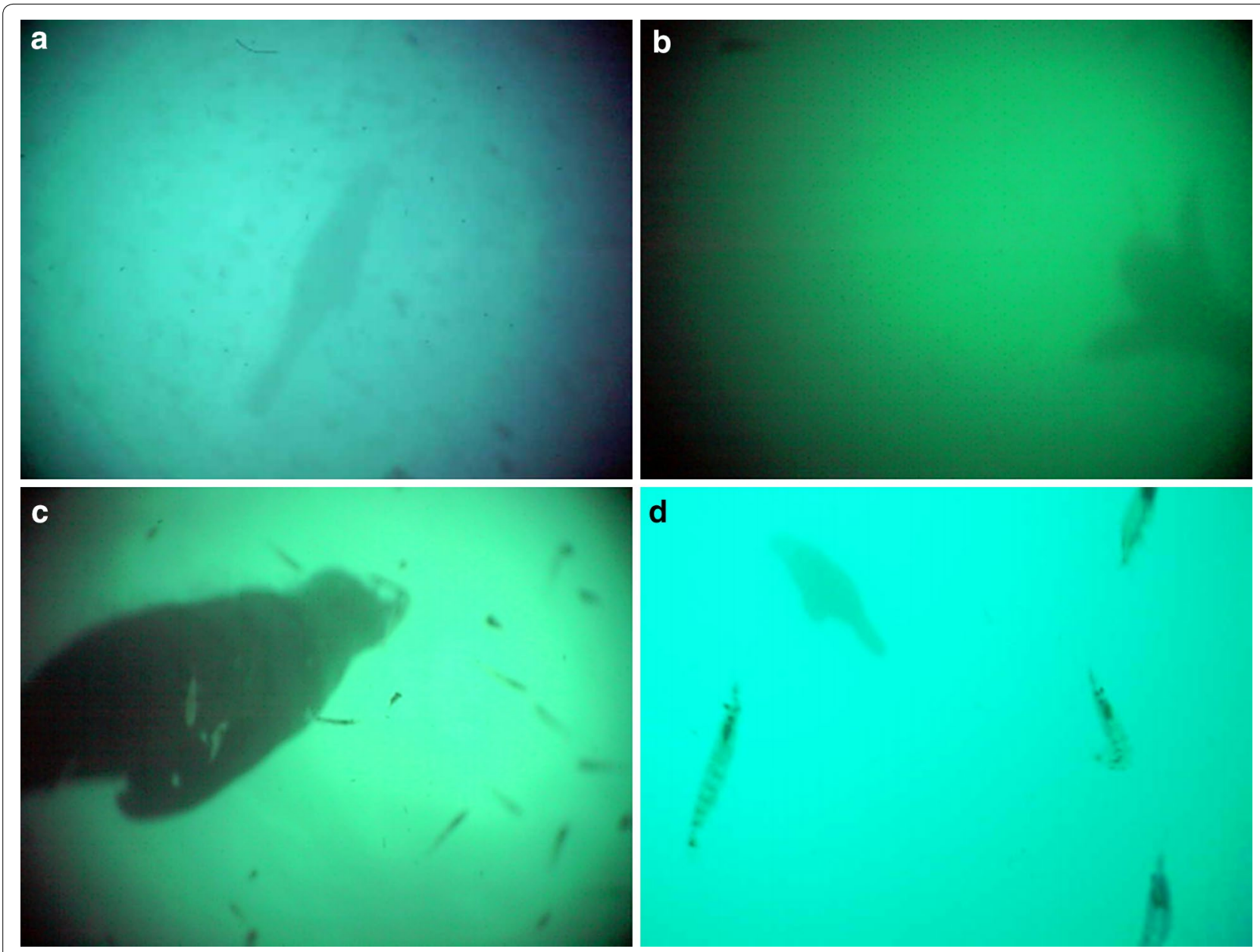

Fig. 2 Examples of images collected from diving fur seals. a w2955 \#0092, 21 m depth, b w6726 \#0213, 27 m depth, c w6728 \#0720, 23 m depth, d w6568 \#2390, 44 m depth

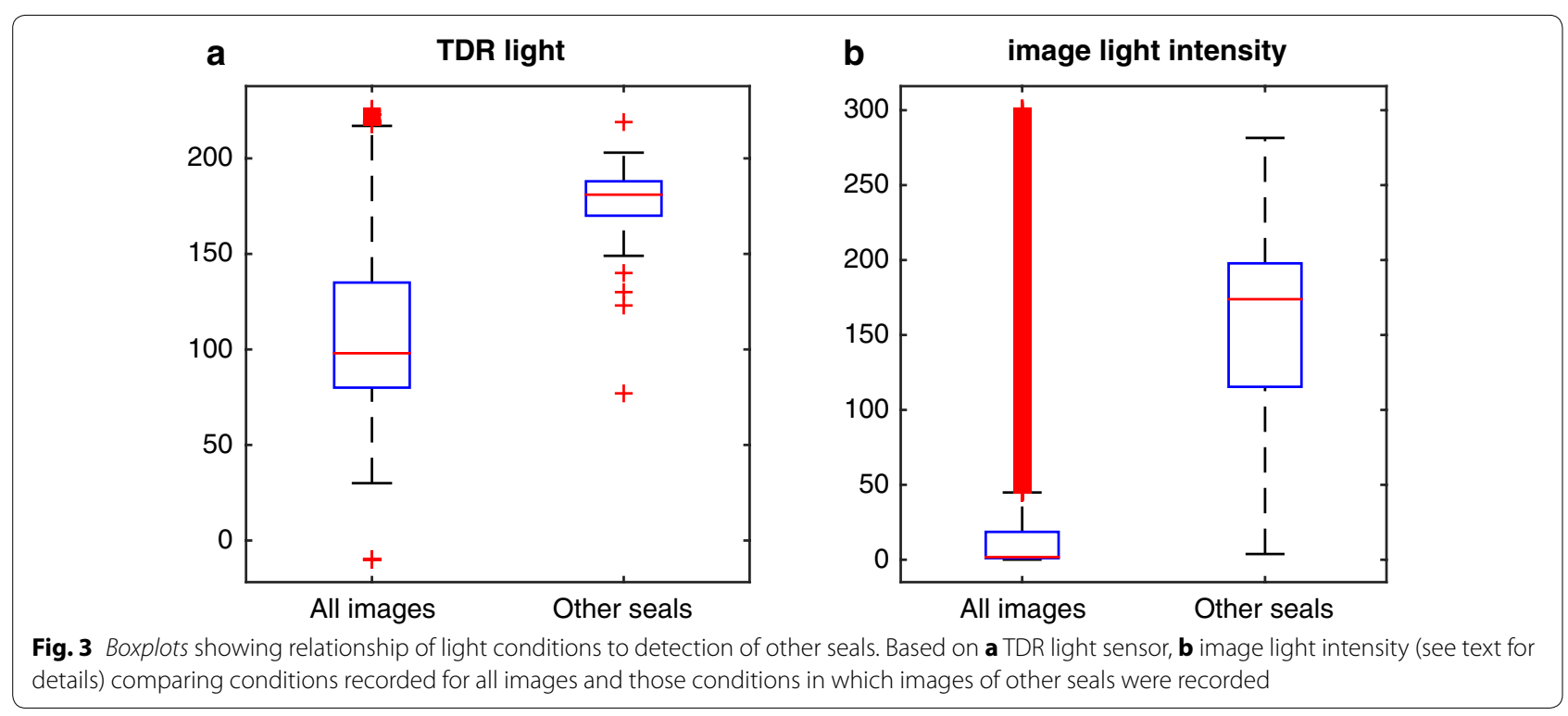


therefore, be unlikely to be detected and reliably identified under flash conditions. Given these detection difficulties, we cannot measure the frequency at which fur seals feed in groups, but our observations are useful to examine how fur seals are oriented spatially relative to each other during diving.

In hindsight, we might have had better detection success by increasing the camera capacity to include sampling at the surface. Our camera system was constrained in terms of battery and data storage, so we attempted to maximize the temporal spread of footage by sampling only during dives when seals were at $>10 \mathrm{~m}$ depth (see Hooker et al. [28] for additional sampling considerations). Future work on sociality might do better to set different limits. For instance, obtaining $30 \mathrm{~s}$ footage after the ascent trigger prior to turning the camera off would provide more details on numbers of seals at the surface. Improvements in battery and memory capacity will also help to avoid these constraints.

\section{Links with dive and bout characteristics}

Other seals were recorded at a range of depths (average $27 \pm 14.3 \mathrm{~m}$, $\max 66 \mathrm{~m}$ ). The majority of images of other seals were in clear water (i.e. did not have krill in the picture, $n=83$ ). The video records tended to show temporal sequences of other seals, then thick krill swarms, then other seals, suggesting seals were oriented around a swarm of krill.

Of 517 dive bouts recorded in still image footage, 330 were single dives (i.e. had $>2 \mathrm{~min}$ at the surface before and after the dive) of which only five contained other seals. The other 187 bouts ranged from 2 to 62 recorded dives. Other seals were recorded in bouts of varying length (2-24 dives). Time of observation during the bout was random (seals were seen at beginning, middle and end of bouts, irrespective of the number of dives in that bout). Examining these data on a dive-bydive basis allows exploration of krill encounter rate and seal encounter rate with other features of dives. Development of linear mixed models for encounter rate of other seals showed a slight increase in encounter rate of other seals with depth, although the fit was very poor $\left(R^{2}=0.019\right)$. Average frequency of other seal encounters was higher in austral summer 2000, than in 2001 and 2002 (Tukeys Honest Significant differences, $p<0.01$ ), but differences between 2001 and 2002 were not significant $(p=0.30)$. Such interannual differences in prey biomass are well reported and likely drive this difference in detection of conspecifics [29-31]. The frequency of other seal encounters appeared to increase with the total krill encounter rate. This relationship was stronger for krill encounter rate for certainty threshold $>2$ (i.e. distinct krill, $t_{1470}=3.47, p<0.01$ ). There was also evidence for a relationship between other seal encounter rate and time of day $\left(t_{1470}=2.85, p<0.01\right)$ confirming difficulties with detection of other seals at night.

\section{Implications in terms of prey detection and foraging models}

These results could have several implications in terms of fur seal behaviour. How fur seals target krill swarms is largely unknown. Several studies have shown that seabirds are able to detect prey swarms due to olfactory detection of dimethyl sulfide produced by phytoplankton in response to zooplankton grazing [32, 33]. Experimental work has shown that seals also have a high olfactory sensitivity for atmospheric DMS [34] and so may use this to detect prey patches. Alternatively, seals could use acoustic cues either of the krill swarms themselves or of other fur seals. Experimental work has confirmed that grey seals can learn to use audible cues as an indicator of food location [35]. Observations of audible ascent exhalations from all dives of fur seals [36], combined with the presence of multiple animals at a foraging patch (demonstrated here), suggests that a searching seal might 'hear' other foraging seals.

Various studies have attempted to link predator behaviour to prey field density (e.g., [31, 37]. However, the presence of conspecifics is likely to be a confounding factor. We show here a relationship between presence of conspecifics and krill density. Whether thick krill swarms are more likely to be targeted by multiple predators, or whether multiple predators cause the krill swarm to become more compact, is unclear as are the implications of this in terms of the energy gain function for an individual seal. Indeed, Krause and Ruxton [7] suggest that for situations such as these (although they give the example of seabirds feeding on shoaling near-surface fish) the resource is so apparently bountiful that depletion by others does not measurably decrease the food available to any one individual. This is unlikely to be the case for fur seals, since patch quality has been shown to decrease during foraging bouts [31]. Theoretical consideration of the effect of grouped predators on functional response curves would be useful. We might expect multiple predators that coalesce a prey swarm would increase the immediate individual prey acquisition rate, but whether this would result in overall individual gains is unclear. Indeed, the sigmoidal gain functions recently observed for a penguin-krill system [38] could potentially be explained by the presence of multiple predators.

\section{Orientations and distances between foraging conspecifics}

Cameras on foraging fur seals provide the opportunity for hypothesis testing as to whether there are differences in orientation of animals relative to each other during a 
dive. In order to minimize camera battery drain, the camera was switched off after $2 \mathrm{~min}<10 \mathrm{~m}$. It then took a 45 -s warmup prior to triggering (at $10 \mathrm{~m}$ depth) on the next dive. This imposed limitations in the collection of images during descent of the first dive in a bout. Thus, more images were taken at the bottom and during the ascent of first dives than at the surface or during descent. In addition, descent images tended to be oriented consistently downwards and so were less likely to have sufficient light for detection of other seals. However, using the TDR light $(>150)$ as a proxy for effort (i.e. appropriate conditions in which to detect other seals, Fig. 3), we can examine how many seals were observed relative to the total number of images taken in good light conditions. It can be seen from this that other seals were most likely to be detected at the bottom of dives (Table 2). Further examination of the orientation and distances at which other seals were observed relative to the instrumented seal showed that animals tended to be slightly closer together and more likely oriented perpendicularly to each other or towards each other at the bottom of dives (Fig. 4). In fact, examining only those images containing multiple seals it can be seen that seals tended to be moving in opposition or perpendicular to each other at the bottom of dives and in synchrony during ascent (Fig. 5).

The manner of foraging in these seals, therefore, appears quite different to that observed for penguins using a similar animal-attached camera system. Penguins appear to swim in the same direction as each other for the majority $(80 \%)$ of the time [21]. Takahashi et al. [21]

Table 2 Dive cycle phase, likelihood of recording other seals, and their orientations

\begin{tabular}{|c|c|c|c|c|c|c|c|}
\hline & \multirow[t]{2}{*}{ All images } & \multirow[t]{2}{*}{ Light images } & \multirow[t]{2}{*}{ Other seals } & \multirow{2}{*}{$\begin{array}{l}\text { Proportion (\% seals vs. } \\
\text { light images) }\end{array}$} & \multicolumn{3}{|c|}{ Orientation } \\
\hline & & & & & Same & Perpendicular & Towards \\
\hline Dive descent & 6012 & 1478 & 4 & 0.3 & 0 & 2 & 2 \\
\hline Dive bottom & 21,591 & 3109 & 66 & 2.1 & 9 & 54 & 3 \\
\hline Dive ascent & 10,171 & 2975 & 49 & 1.6 & 34 & 6 & 9 \\
\hline Surface & 299 & 130 & 2 & 1.5 & 0 & 2 & 0 \\
\hline$n$ & & & & & 43 & 64 & 14 \\
\hline
\end{tabular}

Proportion of other seals observed is given relative to the number of light images (using TDR light $>150$ as a proxy for detectability of other seals). Orientations of observed seals are shown relative to the instrumented seal

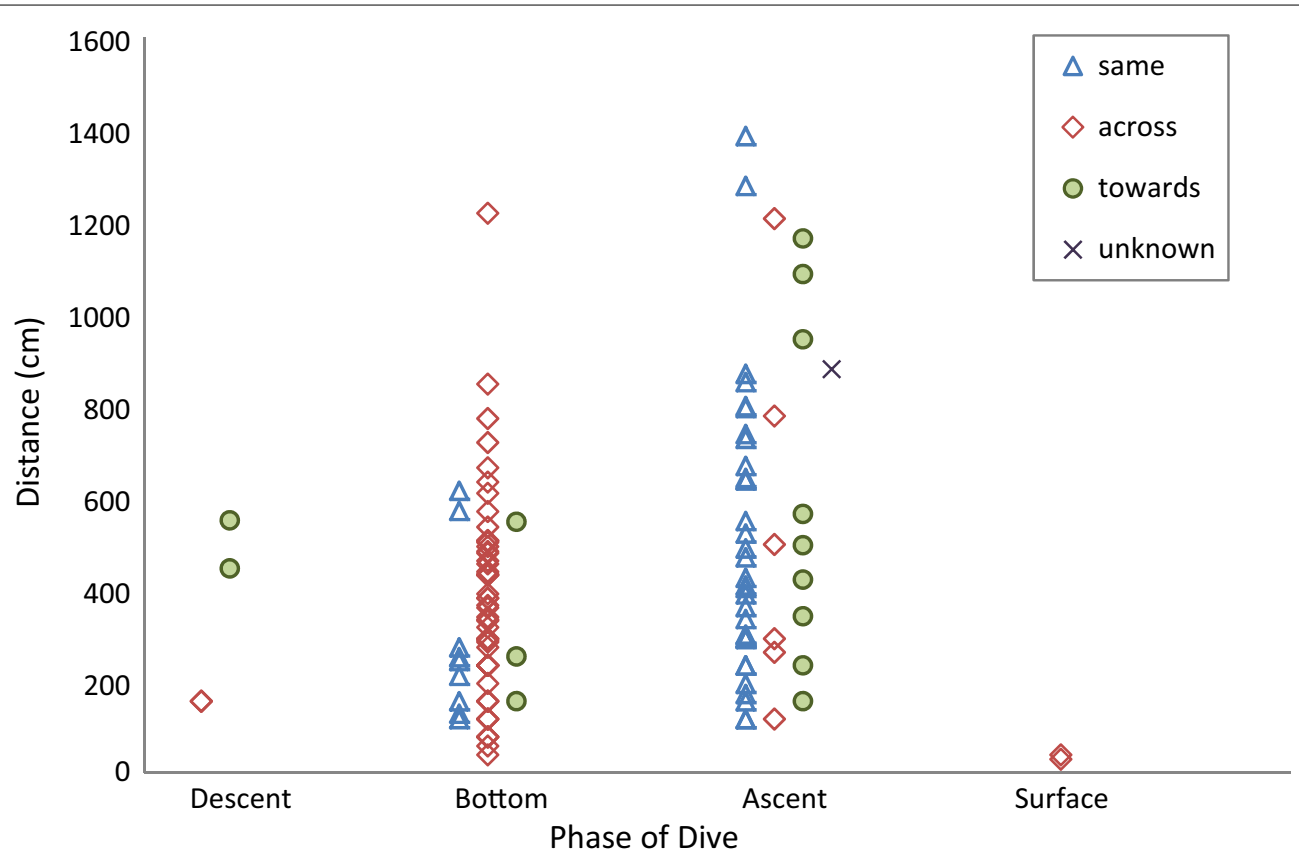

Fig. 4 Orientations and distances between instrumented and observed seals at different phases of the dive cycle. Orientations between two seals were classified as 'same' when animals were travelling in the same direction, 'towards' when travelling in opposite directions, and 'across' when one seal was travelling perpendicular to the direction of the other 

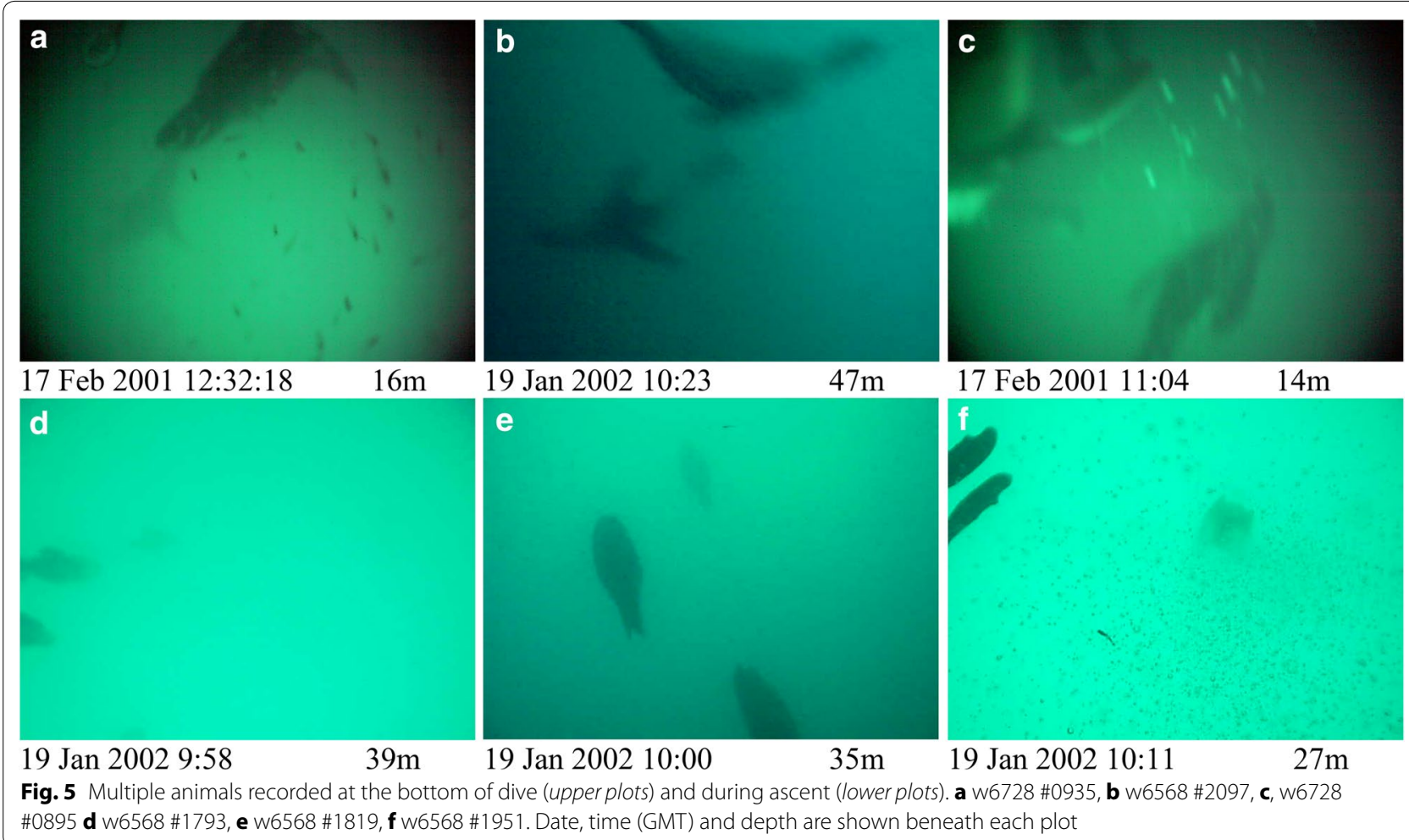

19 Jan 2002 9:58

\section{$39 \mathrm{~m}$}

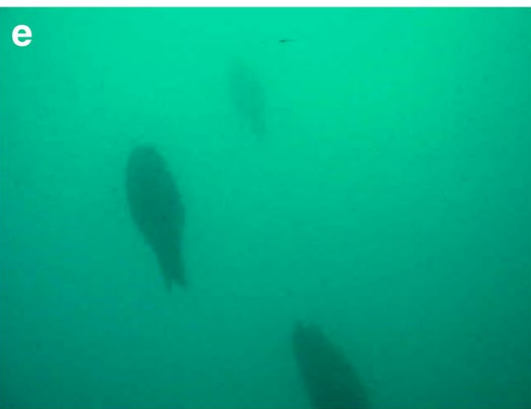

Fig. 5 Multiple animals recorded at the bottom of dive (upper plots) and during ascent (lower plots). a w6728 \#0935
$\# 0895$ d w6568 \#1793, e w6568\#1819, f w6568 \#1951. Date, time (GMT) and depth are shown beneath each plo

suggested that such orientation at the bottom of dives indicated that penguins were not feeding in a coordinated way. Our observations suggest that fur seals are least likely to swim in the same direction as each other at the bottom of dives, but appear to be orienting themselves relative to each other. Whether this could represent coordinated foraging is not yet clear.

Co-ordinated foraging has been recorded in another krill predator-the crabeater seal, Lobodon carcinophagus $[39,40]$. Surface ship-based observers witnessed large numbers of seals surfacing and diving synchronously. The authors suggest that seals were either 'herding' the krill swarm or disrupting the efficiency of the prey's avoidance strategies to lead to an increase in prey capture rate. Co-operative herding has been suggested for several other pelagic predators and was investigated for the spinner dolphin, Stenella longirostris [8]. Thought to feed on shrimp, squid and lanternfish in the deep-scattering layer, dolphins were suggested to encircle prey patches, which would become 11-12 (and up to 60) times higher in density than the background. These authors suggest that herding of prey occurs most often in featureless environments such as the open ocean, in which case, the Antarctic fur seal would be a prime candidate for which we might expect cooperative herding of prey. Combining accelerometers and cameras would prove beneficial to examine this further, providing information on the prey density, the presence of other animals in the group, and the number of foraging attempts (accelerations) made by the instrumented seal [37]. This would allow examination of both herding behaviour, its affect on prey density, and whether this results in increases in number of prey capture attempts per individual.

\section{Conclusions}

We report here the dynamics of conspecific fur seals foraging at sea, as observed via animal-attached cameras. Despite suggestions of multi-predator competition for krill, no predators other than conspecific fur seals were detected in images. Likelihood of detection was primarily limited by light conditions. Other seals tended to be associated with prey availability. Seals were closest and oriented perpendicular to each other at the bottom of dives. In comparison to proximity tags, images can provide only relatively short-range detail on other seals $(0-14 \mathrm{~m}$ distances), and are not of sufficient resolution for individual identification of other seals. However, they can provide details about relative postures and orientation between seals that proximity tags could not. Interestingly, while we are unable to confirm the presence of co-ordinated foraging, we show that foraging fur seals appear oriented in opposition to each other far more than has been observed for foraging penguins [21], suggesting that their behaviour relative to each other at the bottom of dives 
may be rather different. This work confirms the utility of camera technology for providing insight into finescale foraging tactics, providing close-range observations unachievable by other means.

\section{Authors' contributions}

SKH and MJ performed fieldwork, SKH and MJ conducted initial processing of images. SKH, MJ, IJST and TB discussed hypotheses and completed the analyses. All authors commented on drafts and approved the final manuscript.

\section{Author details \\ 1 Sea Mammal Research Unit, Scottish Oceans Institute, University of St Andrews, Fife KY16 8LB, UK. ${ }^{2}$ Scottish Oceans Institute, University of St Andrews, Fife KY16 8LB, UK. ${ }^{3}$ Present Address: Centre for Biodiversity and Envi- ronmental Research, UCL, London WC1E 6BT, UK. ${ }^{4}$ SFI MaREI Centre, Beaufort, Environmental Research Institute, University College Cork, Cork, Ireland. ${ }^{5}$ British Antarctic Survey, Natural Environmental Research Council, High Cross, Madingley Road, Cambridge CB3 OET, UK.}

\section{Acknowledgements}

We thank field staff at the British Antarctic Survey's Bird Island research station for assistance with deployments and recovery of instrumentation used in this study. Nick Warren and Susan Heaslip helped catalogue data from the camera deployments. This work was conducted under the British Antarctic Science programme DYNAMOE. The paper benefitted from helpful comments by two reviewers.

\section{Compliance with ethical guidelines}

\section{Competing interest}

The authors declare that they have no competing interests.

Received: 2 February 2015 Accepted: 11 September 2015

Published online: 29 September 2015

\section{References}

1. Gentry RL, Kooyman GL. Fur seals. Maternal strategies on land and at sea. Princeton: Princeton University Press; 1986.

2. Tremblay $Y$, Cherel $Y$. Synchronous underwater foraging behavior in penguins. Condor. 1999;101:179-85. doi:10.2307/1370462.

3. Insley S. Long-term vocal recognition in the northern fur seal. Nature. 2000:406:404-5. doi:10.1038/35019064.

4. Insley SJ, Phillips AV, Charrier I. A review of social recognition in pinnipeds. Aquat Mamm. 2003;29:181-201. doi:10.1578/016754203101024149.

5. Pitcher BJ, Harcourt RG, Charrier I. The memory remains: long-term vocal recognition in Australian sea lions. Anim Cogn. 2010;13:771-6. doi:10.1007/s10071-010-0322-0.

6. Tripovich JS, Charrier I, Rogers TL, Canfield R, Arnould JPY. Who goes there? Differential responses to neighbor and stranger vocalizations in male Australian fur seals. Mar Mamm Sci. 2008;24:941-8. doi:10.1111/j.1748-7692.2008.00222.x.

7. Krause J, Ruxton GD. Living in groups. Oxford: Oxford University Press; 2002.

8. Benoit-Bird KJ, Au WWL. Cooperative prey herding by the pelagic dolphin, Stenella longirostris. J Acoust Soc Am. 2009;125:125-37. doi:10.1121/1.2967480.

9. Simila T, Ugarte F. Surface and underwater observation of cooperatively feeding killer whales in northern Norway. Can J Zool. 1993;71:1494-9. doi:10.1139/z93-210.

10. Wiley D, Ware C, Bocconcelli A, Cholewiak D, Friedlaender A, Thompson $M$, et al. Underwater components of humpback whale bubble-net feeding behaviour. Behaviour. 2011;148:575-602. doi:10.1163/0005795 $11 \times 570893$

11. Reid K, Arnould JPY. The diet of Antarctic fur seals Arctocephalus gazella during the breeding season at South Georgia. Polar Biol. 1996;16:105-14. doi:10.1007/BF02390431.
12. Boyd IL, Croxall JP. Diving behaviour of lactating Antarctic fur seals. Can Zool. 1992;70:919-28. doi:10.1139/z92-131.

13. Boyd IL, Arnould JPY, Barton T, Croxall JP. Foraging behaviour of Antarctic fur seals during periods of contrasting prey abundance. J Anim Ecol. 1994;63:703-13. doi:10.2307/5235.

14. Staniland IJ, Robinson SL. Segregation between the sexes: Antarctic fur seals, Arctocephalus gazella, foraging at South Georgia. Anim Behav. 2008;75:1581-90. doi:10.1016/j.anbehav.2007.10.012.

15. Hunt GL, Heinemann D, Everson I. Distributions and predator-prey interactions of macaroni penguins, Antarctic fur seals, and Antarctic krill near Bird Island, South Georgia. Mar Ecol Prog Ser. 1992;86:15-30. doi:10.3354/ meps086015.

16. Reid K, Sims M, White RW, Gillon KW. Spatial distribution of predator/ prey interactions in the Scotia Sea: implications for measuring predator/ fisheries overlap. Deep Sea Res II Top Stud Oceanogr. 2004;51:1383-96. doi:10.1016/j.dsr2.2004.06.007.

17. Rutz C, Burns ZT, James R, Ismar SMH, Burt J, Otis B, et al. Automated mapping of social networks in wild birds. Curr Biol. 2012;22(17):R669-71. doi:10.1016/j.cub.2012.06.037.

18. Boyd IL. Pup production and distribution of breeding Antarctic fur seals (Arctocephalus gazella) at South Georgia. Antarct Sci. 1993;5:17-24. doi:10.1017/S0954102093000045.

19. Sato K, Mitani Y, Kusagaya H, Naito Y. Synchronous shallow dives by Weddell seal mother-pup pairs during lactation. Mar Mamm Sci. 2003;19:38495. doi:10.1111/j.1748-7692.2003.tb01116.x.

20. Aoki K, Sakai M, Miller PJO, Visser F, Sato K. Body contact and synchronous diving in long-finned pilot whales. Behav Process. 2013;99:12-20. doi:10.1016/j.beproc.2013.06.002.

21. Takahashi A, Sato K, Naito Y, Dunn MJ, Trathan PN, Croxall JP. Penguinmounted cameras glimpse underwater group behaviour. Proc R Soc Lond B (Suppl). 2004;271:S281-2. doi:10.1098/rsbl.2004.0182.

22. Hooker SK, Boyd IL, Jessopp M, Cox O, Blackwell J, Boveng PL, et al. Monitoring the prey-field of marine predators: combining digital imaging with datalogging tags. Mar Mamm Sci. 2002;18:680-97. doi:10.1111/j.1748-7692.2002.tb01066.x.

23. Croxall JP, Reid K, Prince PA. Diet, provisioning and productivity responses of marine predators to differences in availability of Antarctic krill. Mar Ecol Prog Ser. 1999:177:115-31. doi:10.3354/meps177115.

24. Reid K, Croxall JP. Environmental response of upper trophic-level predators reveals a system change in an Antarctic marine ecosystem. Proc $R$ Soc Lond B. 2001;268:377-84. doi:10.1098/rspb.2000.1371

25. Barlow KE, Boyd IL, Croxall JP, Reid K, Staniland IJ, Brierley AS. Are penguins and seals in competition for Antarctic krill at South Georgia? Mar Biol. 2002;140:205-13. doi:10.1007/s00227-001-0691-7.

26. Waluda CM, Collins MA, Black AD, Staniland IJ, Trathan PN. Linking predator and prey behaviour: contrasts between Antarctic fur seals and macaroni penguins at South Georgia. Mar Biol. 2010;157:99-112. doi:10.1007/ s00227-009-1299-6.

27. Heaslip SG, Hooker SK. Effect of animal-borne camera and flash on the diving behaviour of the female Antarctic fur seal (Arctocephalus gazella). Deep Sea Res I Oceanogr Res Pap. 2008;55:1179-92. doi:10.1016/j. dsr.2008.05.006

28. Hooker SK, Heaslip SG, Matthiopoulos J, Cox O, Boyd IL. Data sampling options for animal-borne video cameras: considerations based on deployments with Antarctic fur seals. Mar Technol Soc J. 2008;42:65-75. doi:10.4031/002533208786829179.

29. Brierley AS, Watkins JL, Murray AWA. Interannual variability in krill abundance at South Georgia. Mar Ecol Prog Ser. 1997;150:87-98. doi:10.3354/ meps150087.

30. Fielding S, Watkins JL, Trathan PN, Enderlein P, Waluda CM, Stowasser G, et al. Interannual variability in Antarctic krill (Euphausia superba) density at South Georgia, Southern Ocean: 1997-2013. ICES J Mar Sci. 2014;71:2578-88. doi:10.1093/icesjms/fsu104.

31. Mori Y, Boyd IL. The behavioral basis for nonlinear functional responses and optimal foraging in Antarctic fur seals. Ecology. 2004;85:398-410. doi:10.1890/03-4005.

32. Nevitt GA, Veit RR, Kareiva P. Dimethyl sulfide as a foraging cue for Antarctic Procellariiform seabirds. Nature. 1995;376:680-2. doi:10.1038/376680ao. 
33. Amo L, Rodriguez-Girones MA, Barbosa A. Olfactory detection of dimethyl sulphide in a krill-eating Antarctic penguin. Mar Ecol Prog Ser. 2013;474:277-85. doi:10.3354/meps10081.

34. Kowalewsky S, Dambach M, Mauck B, Dehnhardt G. High olfactory sensitivity for dimethyl sulphide in harbour seals. Biol Lett. 2006;2:106-9. doi:10.1098/rsbl.2005.0380.

35. Stansbury AL, GotzT, Deecke VB, Janik VM. Grey seals use anthropogenic signals from acoustic tags to locate fish: evidence from a simulated foraging task. Proc R Soc Lond B. 2015;282:20141595. doi:10.1098/ rspb.2014.1595.

36. Hooker SK, Miller PJO, Johnson MP, Cox OP, Boyd IL. Ascent exhalations of Antarctic fur seals: a behavioural adaptation for breath-hold diving? Proc R Soc Lond B. 2005;272:355-63. doi:10.1098/rspb.2004.2964.
37. Viviant M, Monestiez P, Guinet C. Can we predict foraging success in a marine predator from dive patterns only? Validation with prey capture attempt data. PLoS One. 2014;9:e88503. doi:10.1371/journal. pone.0088503.

38. Watanabe $Y Y$, Ito M, Takahashi A. Testing optimal foraging theory in a penguin-krill system. Proc R Soc Lond B. 2014;181:20132376. doi:10.1098/ rspb.2013.2376.

39. Gales NJ, Fraser WR, Costa DP, Southwell C. Do crabeater seals forage cooperatively? Deep Sea Res II Top Stud Oceanogr. 2004;51:2305-10. doi:10.1016/j.dsr2.2004.07.006.

40. Gottfried MD. Cooperative foraging behaviour by crabeater seals (Lobodon carcinophaga) at Pleneau Island. Antarctic Peninsula. Antarct Sci. 2014;26:263-4. doi:10.1017/s0954102013000941.
Submit your next manuscript to BioMed Central and take full advantage of:

- Convenient online submission

- Thorough peer review

- No space constraints or color figure charges

- Immediate publication on acceptance

- Inclusion in PubMed, CAS, Scopus and Google Scholar

- Research which is freely available for redistribution

Submit your manuscript at

www.biomedcentral.com/submit

O) BioMed Central 